\title{
Application Of Health Detector (AHD) Dalam Mendeteksi Kesehatan Tubuh Berbasis Android
}

\author{
Ade Silvia Handayani*¹, Martinus Mujur Rose ${ }^{2}$, Ratri Agustina ${ }^{3}$, Ahmad Taqwa $^{4}$, \\ Nyayu Latifah Husni ${ }^{5}$ \\ ${ }_{1,2,3,4,5}$ Politeknik Negeri Sriwijaya; Jl. Srijaya Negara Bukit Besar 30139 \\ 1,2,3,4,5 Jurusan Teknik Elektro, Politeknik Negeri Sriwijaya Palembang \\ e-mail: * ${ }^{1}$ ade_silvia@polsri.ac.id, ${ }^{2}$ mujurrose@yahoo.com, ${ }^{3}$ ratriagustina@gmail.com, \\ 4a_taqwa@yahoo.com, ${ }^{5}$ nyayu_latifah@polsri.ac.id
}

\begin{abstract}
Abstrak
Wireless Body Area Network (WBAN) merupakan perangkat elektronik yang menggunakan metode jaringan sensor untuk bertujuan diterapkan di peralatan medis. Dalam beberapa tahun terakhir, minat terhadap WBAN semakin meningkat karena telah menjadi bidang penelitian yang penting. Pada penelitian ini akan merancang aplikasi android Application Of Health Detector (AHD) untuk mendeteksi kesehatan tubuh. Aplikasi yang telah dirancang sudah berhasil mendeteksi kesehatan tubuh secara otomatis dengan menampilkan nilai dari masing-masing pembacaan sensor, yakni suhu tubuh, detak jantung, tekanan darah, dan kadar oksigen dalam darah. Teknologi ini menyediakan sistem pemantauan kesehatan jarak jauh secara real time. Melalui penggunaan sensor node pada tubuh manusia untuk mendeteksi kesehatan tubuh dan mengirimkannya ke server serta menampilkan status kesehatan tubuh pada aplikasi android berupa deteksi sehat, indikasi atau butuh tindakan. Penelitian ini telah berhasil menciptakan sebuah aplikasi AHD berbasis android yang dapat digunakan untuk mendeteksi kesehatan tubuh, sehingga mempermudah masyarakat dalam mengetahui kondisi kesehatan.
\end{abstract}

Kata kunci-Wireless Body Area Network, android, aplikasi, kesehatan tubuh

\begin{abstract}
Wireless Body Area Network (WBAN) is an electronic device that uses a sensor network method to be applied in medical equipment. In recent years, interest in WBAN has increased as it has become an important research area. This study will design the Application Of Health Detector (AHD) android application to detect body health. The application created has succeeded in automatically detecting body health by displaying the value of each sensor reading, namely body temperature, heart rate, blood pressure, and oxygen levels in the blood. This technology provides a remote health monitoring system in real-time. Through the use of sensor nodes on the human body to detect body health and send it to the server and display the body's health status on the android application in healthy detection, indication or need for action. It is hoped that this health detection application can make it easier for people to know the condition of their body's health. This research has succeeded in creating an Android-based AHD application that can be used to detect body health, making it easier for the public to know their health conditions.
\end{abstract}

Keywords - Wireless Body Area Network, android, application, body health

\section{PENDAHULUAN}

Pandemi covid -19 terus mengalami jumlah peningkatan setiap harinya. Menurut Organisasi Kesehatan Dunia, ada lebih dari 181 juta permasalahan COVID- 19 yang terdapat di segala dunia sampai saat ini. Oleh karena itu, untuk dapat memantau jumlah pasien yang besar ini, diperlukan teknologi Wireless Body Area Network (WBAN). Teknologi ini menyediakan sistem pemantauan kesehatan jarak jauh secara real time [1][2]. Wireless Body Area Network (WBAN) memiliki banyak aplikasi ke area lain 
seperti pada olahraga, militer, fitness, keselamatan jalan tetapi kegunaan utama nya ialah dalam perawatan kesehatan untuk memantau pasien dan mengumpulkan sinyal fisiologis. Dalam beberapa tahun terakhir, minat terhadap WBAN semakin meningkat karena telah menjadi bidang penelitian yang penting karena kebutuhannya yang semakin meningkat di beberapa bidang [2].

Kemajuan teknologi yang terus tumbuh dengan pesat hingga saat ini, membuat sistem pemantauan pasien dimana pasien dapat dimonitor selama 24 jam dengan teknologi Internet of Things (IoT). Pada penelitian Tarmidi [3] memanfaatkan IoT terhadap benda-benda di sekitar agar bisa terhubung dengan jaringan internet. Secara umum, diketahui bahwa Internet of Things (IoT) merupakan teknologi paradigma baru yang dapat menghubungkan berbagai bidang melalui Internet. Untuk aplikasi perawatan kesehatan yang terhubung dengan IoT [4], disinilah peranan internet of things (IOT) pada WBAN. IoT menyediakan konsep dan teknologi dimana pengguna WBAN dapat mengendalikan sensor node, memantau kondisi sensor node, memantau kesehatan tubuh, memperoleh data dan informasi secara real time, online dan remote melalui perangkat seluler dan perangkat lain di internet dengan sistem operasi android. Teknologi WBAN yang digunakan untuk pertukaran informasi adalah Esp8266, dimana pemilihan teknologi komunikasi tersebut berpengaruh terhadap kinerja WBAN yang efisien dan hemat daya. Karena sebagian besar perangkat berbasis jaringan nirkabel dioperasikan dengan baterai. Tantangan daya hadir dihampir setiap area penerapan jaringan sensor nirkabel. Masalah lainnya yaitu untuk sistem keamanan medis dari gangguan, data fisiologis yang dikumpulkan oleh jaringan sensor adalah informasi kesehatan yang bersifat pribadi. Sangat penting untuk menjaga agar informasi tidak dapat diakses oleh entitas yang tidak berwenang [5].

Sistem pemantauan kesehatan WBAN dapat memberikan manfaat yang beragam pengguna: dari penggemar outdoor yang sehat yang ingin melacak tingkat kebugaran mereka selama berolahraga, kepada pengguna dengan mengganggu kondisi medis atau pasien yang menjalani rehabilitasi [6]. Secara umum, pemantauan kesehatan dilakukan secara teratur, dan pasien harus mengingat gejalanya.Oleh karena itu, aplikasi perawatan medis dari jaringan sensor nirkabel dapat memberikan bantuan di rumah, panti jompo, dan uji klinis dan penelitian augmentasi [5].

Pada paper R. Harini dkk (2017) mengusulkan kerangka kerja pengamatan EKG menggunakan aplikasi android. Kerangka kerja ini bergantung pada sensor EKG, mikrokontroler, dan inovasi android. Menggunakan Pelindung Sensor e-Wellbeing yang memungkinkan board Arduino UNO untuk melakukan aplikasi biometrik dan terapeutik di mana pemeriksaan tanda penting diperlukan dengan memanfaatkan berbagai sensor seperti, Elektrokardiogram (EKG), Detak Jantung, Oksigen dalam Darah (SPO2), Suhu Tubuh, Glukometer, Arus Angin (Pernapasan) dan sebagainya untuk kapasitas informasi dalam web XAMPP digunakan. Kerangka yang diusulkan memungkinkan spesialis untuk melihat parameter fundamental pasiennya dari jarak jauh dan secara progresif dalam waktu yang sebenarnya [7]. Dan Devashri Deshmukh dkk (2017) mengusulkan kerangka kerja pengamatan layanan manusia berbasis android di mana tanda penting pasien, misalnya ketegangan peredaran darah, spo2, detak jantung dan sebagainya diperiksa dan data yang diperoleh oleh sensor dikirim melalui aplikasi android. Semua informasi tersebut menggunakan layanan berbasis web sebagai server pusat dan akan ditampilkan kepada pengguna melalui aplikasi android yang memiliki kelebihan lebih mudah untuk diakses [8].

Platform android ialah suatu platform fitur lunak untuk smartphone berbasis mobile. Sistem operasi android mampu didistribusikan secara terbuka atau dikenal dengan istilah open source, perihal ini memungkinkan untuk para pengembang bisa mengendalikan, memodifikasi ataupun meningkatkan aplikasi sendiri. Sistem ini dibuat supaya internet dapat digunakan pada smartphone sehingga mempermudah user [9]. Pada penelitian Al Fatur, menggunakan aplikasi android teknologi mobile yang bisa tetap diakses tanpa terhalang tempat maupun waktu, dengan syarat harus tetap terkoneksi ke internet [10].

Penerapan teknologi mobile berbasis android pada sistem monitoring kesehatan tubuh dilaksanakan dengan berdasarkan data yang dinyatakan oleh Kementerian Komunikasi dan Informasi menilai tingkat penggunaan internet di Indonesia sangatlah tinggi. Hal itu dikarenakan jumlah pengguna smartphone yang cukup besar mencapai 167 juta atau merupakan 89\% dari total penduduk Indonesia [11]. Berdasarkan data tersebut, dapat dilihat bagaimana perkembangan teknologi smartphone sudah menyebar keseluruh kalangan masyarakat. Penting bagi para developer android untuk menjaga kualitas 
aplikasi yang di buat agar menghasilkan suatu aplikasi yang bermutu dan bermanfaat serta mudah digunakan oleh masyarakat. Salah satu tolak ukur kualitas software dengan penggunaan ISO 9126 [12][13][14].

Pada penelitian ini akan merancang sebuah aplikasi Aplication Of Health Detector (AHD) yang berbasis android, dengan menampilkan nilai masing-masing pembacaan sensor serta deteksi kesehatan tubuh. Pada penelitian ini akan menampilkan data kesehatan tubuh dalam tiga tampilan yaitu tampilan data real-time dan grafik, status kesehatan serta history. Dalam tampilan data real-time, data kesehatan tubuh yang ditampilkan dalam bentuk data terbaru yang dibaca oleh sensor node serta menunjukkan grafik keseluruhan. Pada tampilan status kesehatan, menampilkan deteksi berupa sehat, indikasi atau butuh tindakan. Dalam tampilan history, seluruh informasi data yang sudah direkam oleh sensor node akan ditampilkan dalam bentuk tabel, yang mempermudah untuk melihat informasi data kesehatan pada waktu sebelumnya. Data kesehatan tubuh yang ditampikan pada tiga display tersebut diperoleh dari alat pendeteksi berupa teknologi WBAN dengan multi sensor. Alat pendeteksi tersebut akan mendeteksi serta mengirimkan informasi data kesehatan tubuh berupa suhu tubuh, detak jantung, tekanan darah sistolik dan diastolik, dan kadar oksigen dalam darah, kemudian menampilkannya pada smartphone berbasis aplikasi android dengan menambahkan usia dan jenis kelamin agar dapat menampilkan hasil deteksi kesehatan.

\section{METODE PENELITIAN}

Tahapan dari penelitian ini diawali dari tahap perancangan perangkat keras kemudian perangkat lunak, termasuk metode fuzzy mamdani, serta tahap akhir integrasi dan pengujian sistem. Perancangan perangkat keras sistem deteksi kesehatan manusia menggunakan teknologi WBAN dan digambarkan dalam bentuk alat melalui diagram blok sistem singkat. Ini bertujuan agar mengetahui bentuk umum perangkat keras yang akan dirancang.

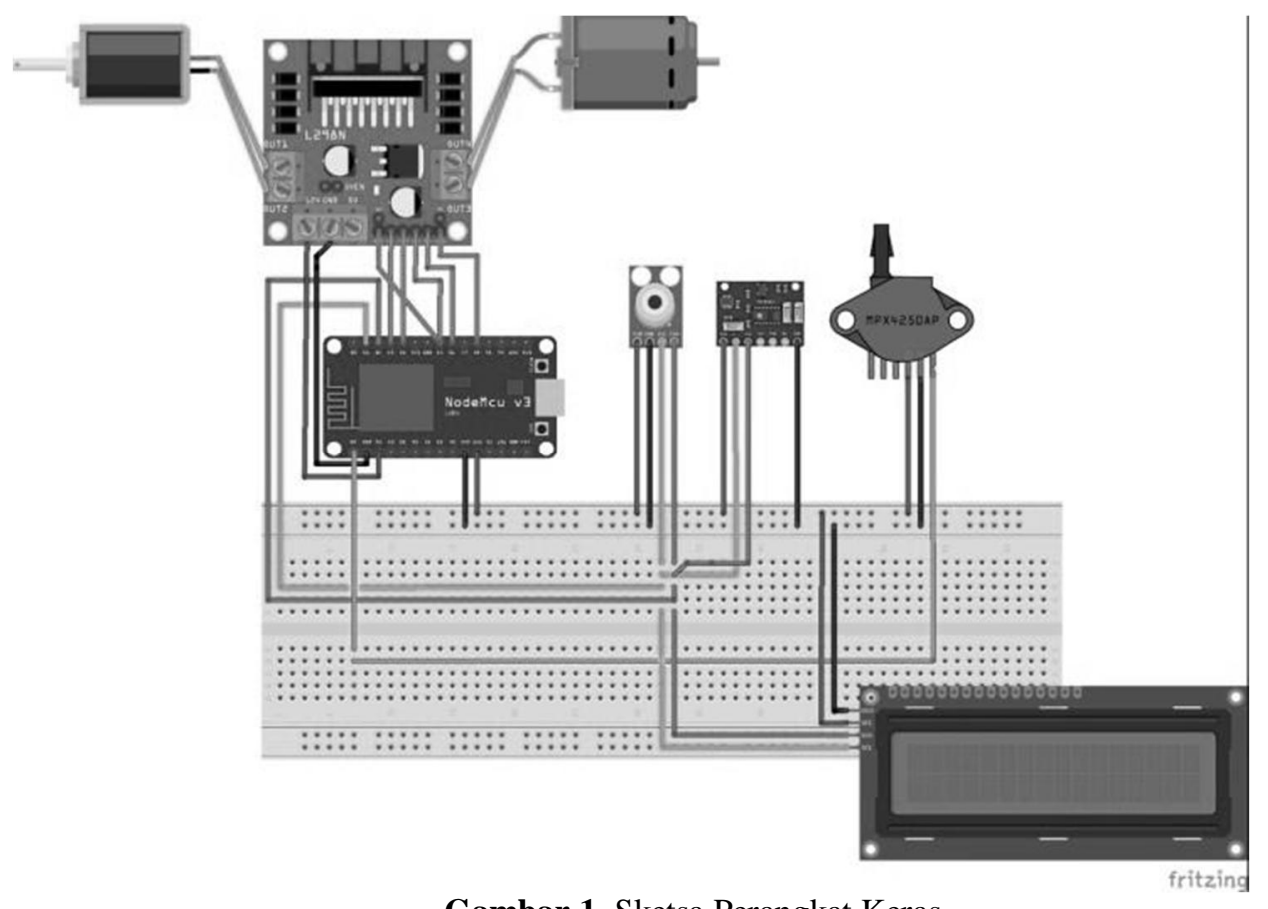

Gambar 1. Sketsa Perangkat Keras 


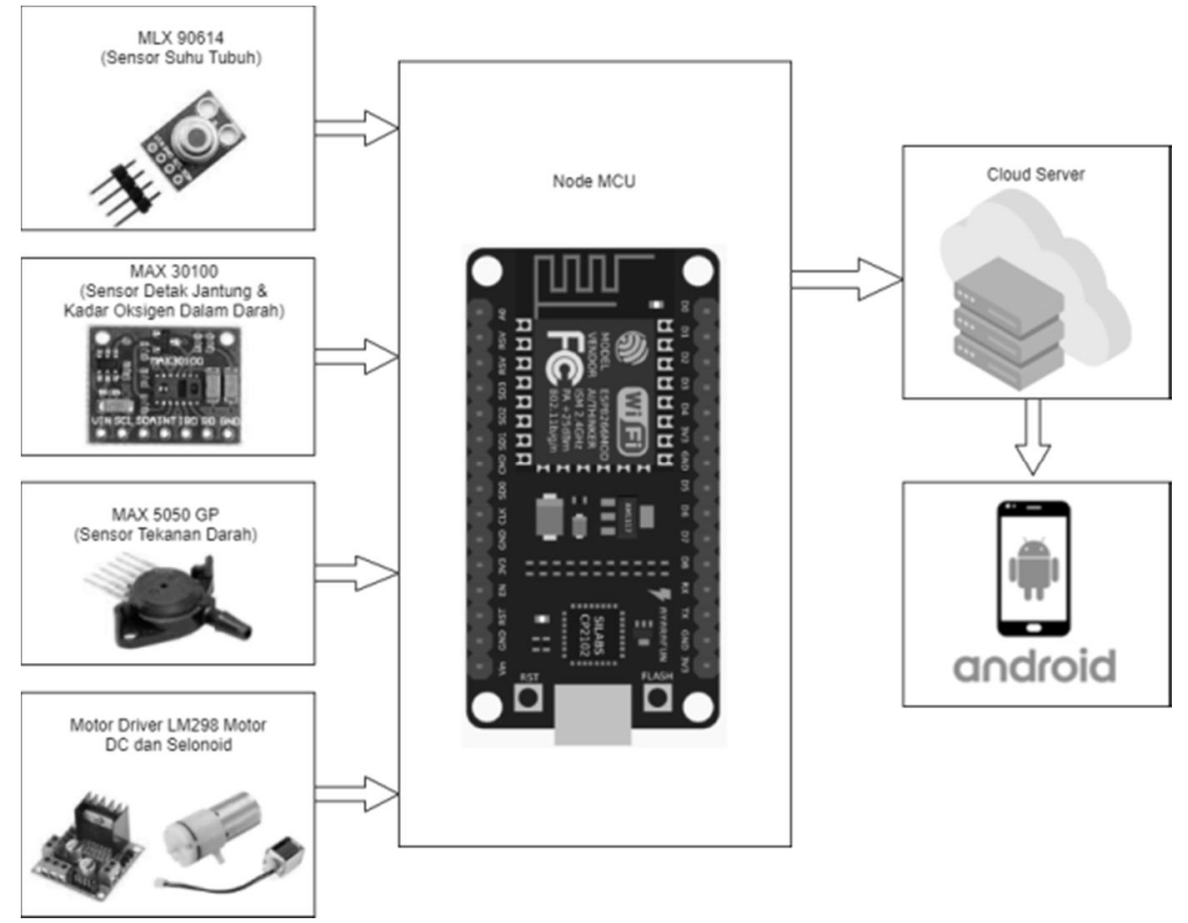

Gambar 2. Blok Sketsa Sistem Sensor

Pada Gambar 2, ialah hasil rancangan sistem deteksi kesehatan tubuh memakai 3 sensor node. Setiap sensor node terdiri dari beberapa komponen pendukung seperti pada Gambar 1. sistem pendeteksi kesehatan tubuh ini, di rancang menggunakan mikrokontroller Node $M C U$ yang sudah dilengkapi dengan modul WIFI ESP8266 didalamnya, menggunakan sensor MLX 90614 sebagai sensor suhu tubuh, sensor MAX 5050 GP sebagai sensor tekanan darah, sensor MAX 30100 sebagai sensor detak jantung dan kadar oksigen dalam darah. Selain itu, digunakan juga Motor Driver sebagai driver untuk Motor DC dan Selenoid ke Node MCU, Motor DC sebagai motor untuk memompa tekanan udara, dan Selenoid sebagai katup untuk mengunci penahan dan pembuang udara. Agar dapat mengirimkan data pembacaan sensor ke server dan dikirim secara real time, NodeMCU ESP8266 yang sudah terkoneksi wifi mengirimkan informasi data hasil pengukuran sensor ke server yang akan ditampilkan di aplikasi android.

Kinerja sistem secara keseluruhan dalam pengujian ini, node sensor akan secara otomatis bekerja mendeteksi kesehatan tubuh dengan menampilkan informasi suhu tubuh, tekanan darah sistolik dan diastolik, detak jantung dan kadar oksigen dalam darah serta memberikan pesan darurat tentang keadaan tubuh (sehat, indikasi, dan butuh tindakan).

Pada gambar 3, ialah gambar dari sistem perangkat lunak yang akan di rancang. Aplikasi android yang akan dirancang menggunakan sofware IDE Android Studio, yang telah terintegrasi dengan bahasa XML dan JAVA.

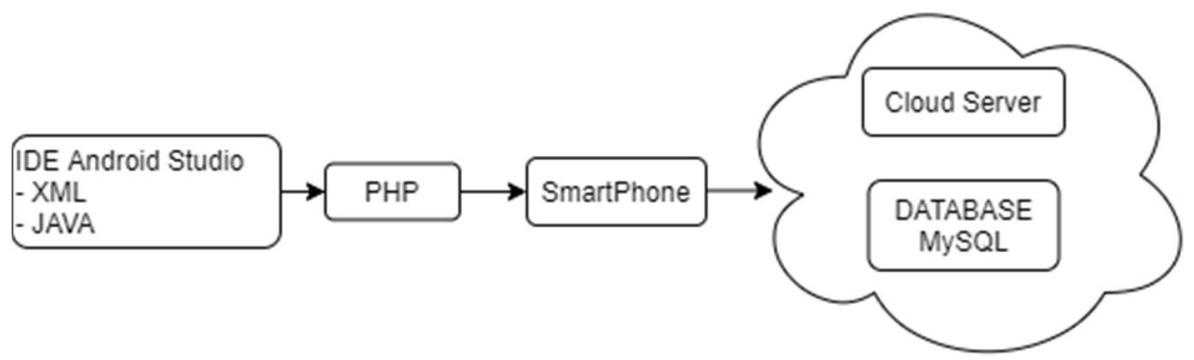

Gambar 3. Blok Sistem Perangkat Lunak 

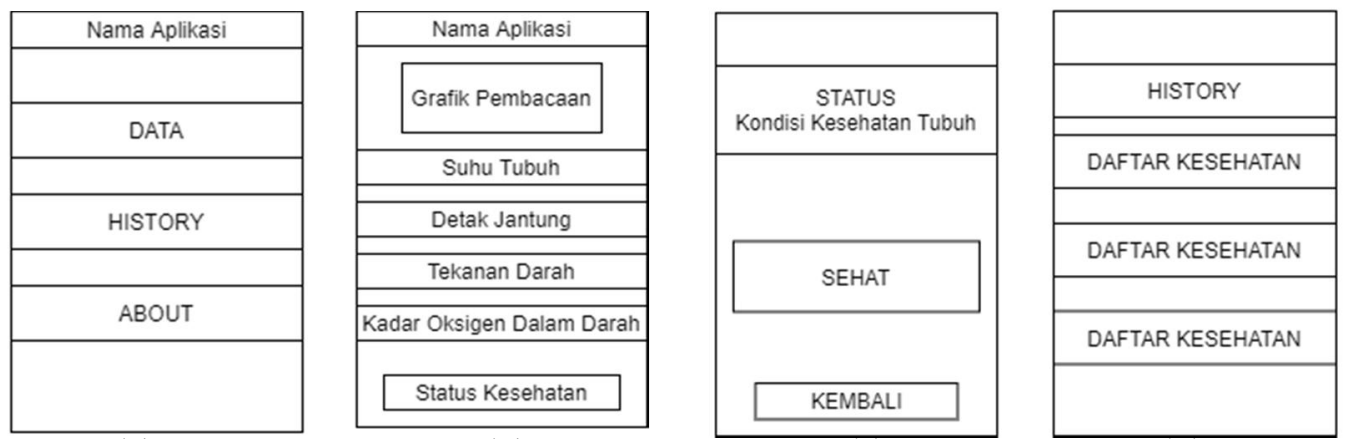

Gambar 4. Skema Layout Aplikasi (a) Menu Utama (b) Real Time Data

(c) Status Kesehatan (d) History

Gambar 4 ialah desain dari tampilan aplikasi yang akan digunakan sebagai skema dalam pembuatan aplikasi. Pada tampilan layout aplikasi android, layout menu utama ditunjukkan pada gambar 4(a) yang terdapat 3 button. Saat button data di klik, maka akan tampil halaman real time data seperti pada 4(b) yang akan menampilkan nilai pembacaan masing-masing sensor serta button status kesehatan yang mana saat di klik akan menampilkan hasil dari deteksi kesehatan seperti pada gambar 4(c). kemudian pada halaman history yang ditunjukkan pada gambar 4(d), yang menampilkan semua data kesehatan tubuh yang direkam oleh sensor node.

Metode pengujian perangkat lunak mengacu pada standar ISO 9126, yang mencakup penerapan functionality, efficiency dan usability.

Metode analisis data informasi yang digunakan merupakan analisis deskriptif dengan rumus perhitungan:

$$
\text { PresentaseKelayakan }(\%) \quad=\frac{\text { skor yang diamati }}{\text { skor yang diharapkan }} \times 100 \%
$$

Setelah mendapatkan data skor dari hasil tes, selanjutnya gunakan rumus untuk menghitung persentase. Setelah itu, ubahlah persentase menjadi pernyataan sesuai tabel 1 berikut ini.

Tabel 1. Persentase Kelayakan

\begin{tabular}{|c|c|c|}
\hline No & Persentase Pencapaian $(\%)$ & Keterangan \\
\hline 1 & $0 \%-20 \%$ & Rendah Sekali \\
\hline 2 & $21 \%-40 \%$ & Rendah \\
\hline 3 & $41 \%-60 \%$ & Cukup Tinggi \\
\hline 4 & $61 \%-80 \%$ & Tinggi \\
\hline 5 & $81 \%-100 \%$ & Sangat Tinggi \\
\hline
\end{tabular}

\section{HASIL DAN PEMBAHASAN}

\subsection{Perancangan Perangkat Keras Sistem Deteksi Kesehatan Tubuh}

Perancangan perangkat keras (hardware) ditempatkan pada suatu kotak akrilik, yang sudah terbuat berdasarkan sketsa rancangan sebelumnya.

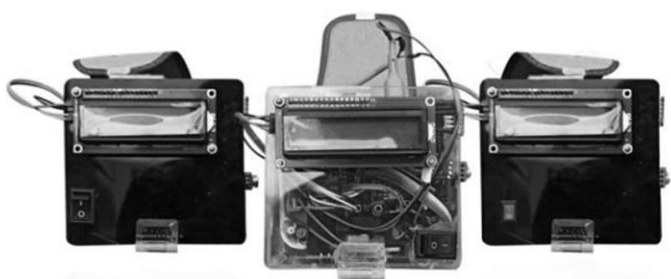

Gambar 5. Perangkat Keras (hardware) 
Pada gambar 5 diatas, ialah bentuk dari alat pendeteksi yang telah dibuat. Sensor-sensor yang digunakan diletakkan didalam sensor node supaya bisa mendeteksi kesehatan tubuh. Adapula sensorsensor yang digunakan yakni sensor MLX 90614 sebagai sensor temperatur suhu tubuh, sensor MAX 5050 GP sebagai sensor tekanan darah, sensor MAX 30100 sebagai sensor detak jantung dan kadar oksigen dalam darah. Selain itu, digunakan juga Motor Driver sebagai driver untuk Motor DC dan Selenoid ke Node MCU, Motor DC sebagai motor untuk memompa tekanan udara, dan Selenoid sebagai katup untuk mengunci penahan dan pembuang udara.

\subsection{Perancangan Perangkat Lunak (Aplikasi) Deteksi Kesehatan Tubuh}

Perangkat fitur lunak sudah sukses terbuat berdasarkan pada blok diagram serta desain layout yang sudah terbuat. Perangkat lunak yang telah dibuat berbentuk suatu aplikasi yang dirancang agar mengetahui kesehatan tubuh yang sudah terhubung dengan smartphone. Pembuatan aplikasi ini memakai software IDE Android Studio. Aplikasi android untuk mendeteksi kesehatan tubuh ini diberi nama "Application of Health Detector (AHD)"

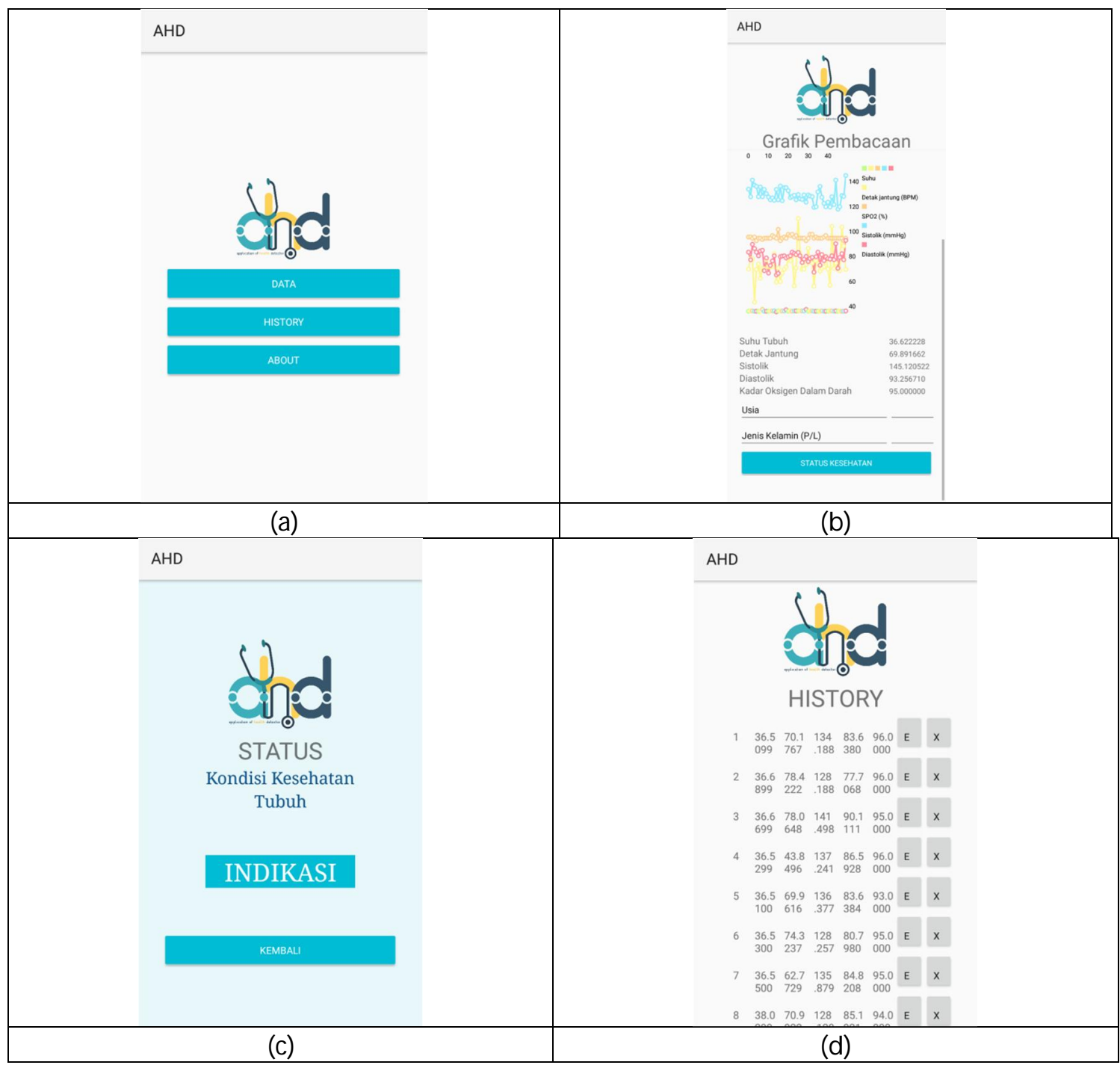

Gambar 6. Tampilan Aplikasi (a) Menu Utama. (b) Data Real-Time. (c) Status Kesehatan. (d) History. 
Pada gambar 6(a) menampilkan menu utama di aplikasi AHD, yang terdiri dari button data, history, dan about. kemudian gambar 6(b) ialah tampilan saat button data ditekan yang merupakan layout real time data, yang mana pada tampilan ini hanya akan menampilkan data terakhir atau terbaru dari kesehatan tubuh yang telah dibaca oleh sensor-sensor kesehatan tubuh secara real time. Pada tampilan real time data terdapat button status kesehatan, yang mana saat button tersebut ditekan akan menampilkan tampilan layout seperti gambar 6(c) yang menampilkan status kesehatan berupa sehat, indikasi atau butuh tindakan. Kembali ke menu utama gambar 6(a) saat button history ditekan, akan menampilkan tampilan seperti pada gambar 6(d). Pada tampilan history akan menunjukkan semua list data pembacaan kesehatan tubuh pada waktu sebelumnya, yang juga disamping tampilan nilai-nilai tersebut terdapat button $\mathrm{X}$ sebagai delete dan button E sebagai edit .

\subsection{Pengujian Aplikasi AHD Dengan Standar ISO 9126}

Tahap ini ialah tahap terakhir untuk pengujian aplikasi. Pengujian dilakukan dengan standar pengujian ISO 9126.

\section{1) Functionality}

Pengukuran Fuctionality dengan menggunakan kuisioner dengan memeriksa fungsi-fungsi pada aplikasi berjalan atau tidak (error).

Tabel 2. Pengukuran Functionality

\begin{tabular}{|c|l|c|c|c|c|c|c|}
\hline \multirow{2}{*}{ No Fitur } & \multicolumn{6}{c|}{ Skor Penguji } & \multirow{2}{*}{ Nilai } \\
\cline { 3 - 7 } & & $\mathbf{1}$ & $\mathbf{2}$ & $\mathbf{3}$ & $\mathbf{4}$ & $\mathbf{5}$ & \\
\hline 1 & Menampilkan Menu Utama & 1 & 1 & 1 & 1 & 1 & 5 \\
\hline 2 & Menampilkan Tampilan Real Time Data & 1 & 1 & 1 & 1 & 1 & 5 \\
\hline 3 & Menampilkan Tampilan History & 1 & 1 & 1 & 1 & 1 & 5 \\
\hline 4 & Menampilkan Tampilan About & 1 & 1 & 1 & 1 & 1 & 5 \\
\hline 5 & Fungsi Setiap Button & 1 & 1 & 1 & 1 & 1 & 5 \\
\hline & Total & 5 & 5 & 5 & 5 & 5 & 25 \\
\hline
\end{tabular}

$$
\begin{aligned}
\text { Presentase Kelayakan }(\%) & =\frac{\text { skor yang diamati }}{\text { skor yang diharapkan }} \times 100 \% \\
& =\frac{25}{25} \times 100 \% \\
& =100 \%
\end{aligned}
$$

Dari pengukuran persentasi yang didapat ialah 100\%, dan dapat disimpulkan bahwa seluruh fitur aplikasi $100 \%$ dapat berjalan dengan baik. Berdasarkan hasil perhitungan presentase kelayakan tersebut, kualitas aplikasi dari sisi functionality memiliki nilai "Sangat Tinggi".

Atau dapat juga dengan rumus $\mathrm{X}=1-\frac{A}{B}$, dimana $\mathrm{X}$ sebagai functionality, A sebagai jumlah total fitur yang tidak valid, dan B sebagai jumlah seluruh fitur.

$$
\mathrm{X}=1-\frac{0}{5}=1
$$

Berdasarkan rumus tersebut, functionality dapat dikatakan baik jika X mendekati 1.

\section{2) Efficiency}

Pengukuran efficiency diukur dengan menghitung rata-rata waktu respon aplikasi untuk launching setiap layout tampilan. Pada pengujian dilakukan 3 kali dengan tiga smartphone berbeda dan spesifikasi berbeda.

Tes 1: Smartphone RAM 3 GB, CPU Qualcomm SDM450 Octa Core

Tes 2: Smartphone RAM 8 GB, CPU Qualcomm Snapdragon 665

Tes 3: Smartphone RAM 2 GB, CPU Qualcomm Snapdragon 425 
Tabel 3. Pengukuran Efficiency

\begin{tabular}{|c|c|c|c|c|}
\hline \multirow{2}{*}{ No } & \multirow{2}{*}{ Kategori } & \multicolumn{3}{|c|}{ Respon Time (s) } \\
\hline & & Tes 1 & Tes 2 & Tes 3 \\
\hline 1 & Menampilkan Logo (Splash Screen) & 3.25 & 3.05 & 3.75 \\
\hline 2 & Menampilkan Tampila Menu Utama & 1.28 & 1.22 & 1.39 \\
\hline 3 & Menampilkan Tampilan Data Real-Time & 0.32 & 0.13 & 0.47 \\
\hline 4 & Menampilkan Status Kesehatan & 0.58 & 0.41 & 0.78 \\
\hline 5 & Menampilkan History & 1.58 & 1.48 & 2.44 \\
\hline 6 & Menampilkan About & 0.8 & 0.6 & 1.02 \\
\hline & Jumlah & 7.81 & 6.89 & 9.85 \\
\hline & Rata-Rata & 1.30 & 1.15 & 1.64 \\
\hline
\end{tabular}

Berdasarkan hasil pengukuran efficiency, didapatkan jika tipe prosesor serta RAM mempengaruhi performa suatu aplikasi. Pengujian pada uji 2 memperoleh hasil lebih cepat dibanding dengan uji 1 serta uji 3. Perihal ini disebabkan untuk uji 2 memakai prosesor serta RAM paling tinggi. Tidak hanya itu, koneksi internet pula pengaruhi cepat dan lambat dalam menampilkan data.

\section{3) Usability}

Pengukuran Usability diujikan untuk mengetahui sejauhmana aplikasi dapat digunakan oleh pengguna, yang dilakukan kepada 30 pengguna dengan sub-karakteristik yaitu:

1. Understandibility: Kemampuan suatu aplikasi untuk dipahami.

2. Learnability : Kemampuan suatu aplikasi untuk dipelajari.

3. Operability : Kemampuan suatu aplikasi untuk dijalankan.

4. Attractiveness : Kemampuan suatu aplikasi dalam menarik pengguna.

Tabel 4. Pengukuran Usability

\begin{tabular}{|c|c|c|c|c|c|c|}
\hline \multirow{2}{*}{ Responden } & \multicolumn{4}{|c|}{ Pernyataan } & \multirow{2}{*}{$\begin{array}{l}\text { Total } \\
\text { Skor }\end{array}$} & \multirow{2}{*}{$\begin{array}{l}\text { Skor } \\
\text { Max }\end{array}$} \\
\hline & Understandibility & Learnability & Operability & Attractiveness & & \\
\hline 1 & 5 & 5 & 5 & 4 & 5 & 24 \\
\hline 2 & 5 & 4 & 5 & 4 & 4 & 22 \\
\hline 3 & 4 & 4 & 5 & 3 & 4 & 20 \\
\hline 4 & 4 & 4 & 4 & 4 & 4 & 20 \\
\hline 5 & 4 & 3 & 4 & 3 & 4 & 18 \\
\hline 6 & 4 & 4 & 5 & 5 & 3 & 21 \\
\hline 7 & 5 & 4 & 5 & 4 & 4 & 22 \\
\hline 8 & 4 & 4 & 4 & 4 & 5 & 21 \\
\hline 9 & 4 & 4 & 5 & 3 & 4 & 20 \\
\hline 10 & 5 & 4 & 5 & 5 & 4 & 23 \\
\hline 11 & 4 & 4 & 5 & 4 & 4 & 21 \\
\hline 12 & 4 & 4 & 5 & 4 & 4 & 21 \\
\hline 13 & 5 & 4 & 5 & 4 & 4 & 22 \\
\hline 14 & 4 & 4 & 4 & 4 & 4 & 20 \\
\hline 15 & 4 & 4 & 4 & 4 & 4 & 20 \\
\hline 16 & 4 & 3 & 3 & 3 & 3 & 16 \\
\hline 17 & 3 & 3 & 5 & 3 & 4 & 18 \\
\hline 18 & 4 & 4 & 4 & 4 & 3 & 19 \\
\hline 19 & 4 & 4 & 5 & 4 & 4 & 21 \\
\hline 20 & 4 & 4 & 5 & 4 & 4 & 21 \\
\hline 21 & 4 & 4 & 5 & 4 & 4 & 21 \\
\hline
\end{tabular}




\begin{tabular}{|l|l|l|l|l|l|l|}
\hline 22 & 5 & 4 & 5 & 4 & 4 & 22 \\
\hline 23 & 4 & 4 & 5 & 4 & 5 & 22 \\
\hline 24 & 4 & 4 & 4 & 4 & 4 & 20 \\
\hline 25 & 4 & 4 & 4 & 3 & 4 & 19 \\
\hline 26 & 3 & 4 & 4 & 4 & 4 & 19 \\
\hline 27 & 5 & 5 & 5 & 5 & 4 & 24 \\
\hline 28 & 4 & 5 & 4 & 4 & 4 & 24 \\
\hline 29 & 4 & 4 & 4 & 4 & 4 & 20 \\
\hline 30 & 5 & 4 & 4 & 4 & 5 & 22 \\
\hline \multicolumn{2}{|l|}{ Jumlah } & & $\mathbf{6 2 3}$ & $\mathbf{7 5 0}$ \\
\hline
\end{tabular}

$$
\begin{aligned}
\text { Presentase Kelayakan }(\%) \quad= & \frac{\text { skor yang diamati }}{\text { skor yang diharapkan }} \times 100 \% \\
& =\frac{623}{750} \times 100 \% \\
& =83 \%
\end{aligned}
$$

Berdasarkan perhitungan tersebut diperoleh persentase $83 \%$ dari perhitungaan usability, maka dapat dikatakan bahwa aplikasi AHD memenuhi standar usability dengan kategori "Sangat Tinggi".

\subsection{Pengujian Aplikasi AHD Dalam Deteksi Kesehatan Tubuh}

Pengujian ini dibuat untuk menguji hasil dari perancangan aplikasi AHD, untuk mengetahui kesehatan tubuh. Pengujian dilakukan dengan menggabungkan aplikasi AHD pada satu buah sensor node agar memperoleh hasil dari deteksi kesehatan tubuh.

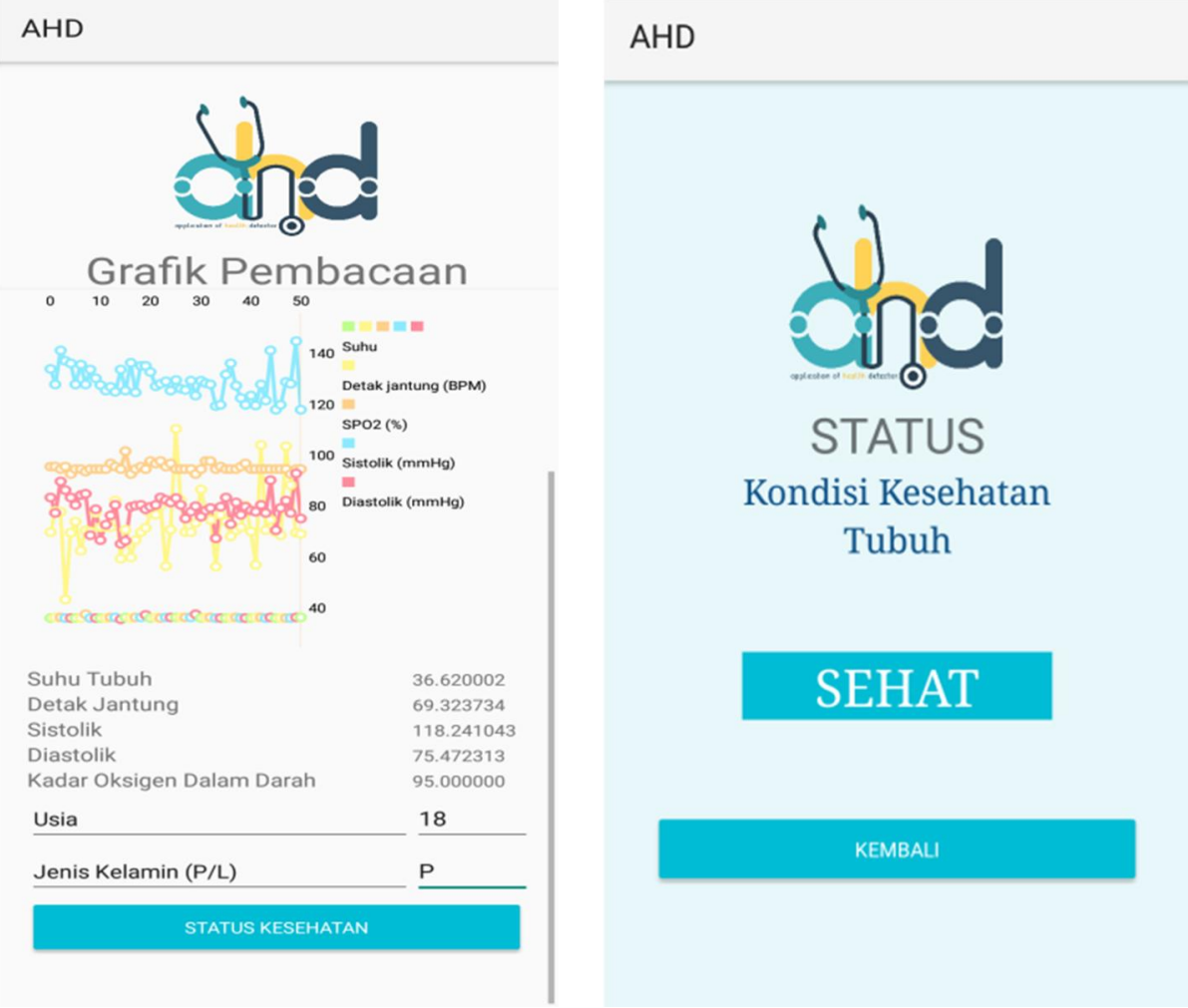

Gambar 7. Tampilan Data Real-Time pada Tanggal 21-06-2021 pada Keadaan Sehat 
AHD

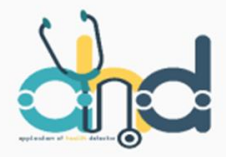

Grafik Pembacaan

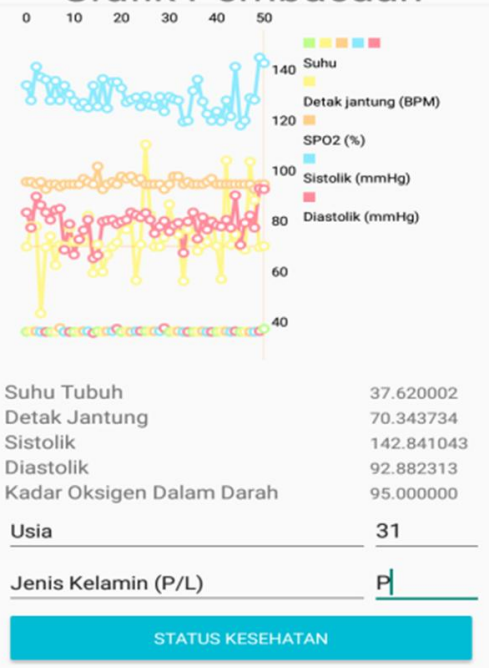

AHD

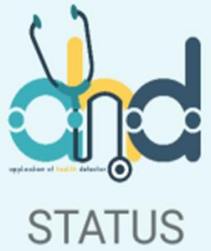

Kondisi Kesehatan Tubuh

\section{INDIKASI}

Gambar 8. Tampilan Data Real-Time pada Tanggal 21-06-2021 pada Keadaan Indikasi AHD

AHD

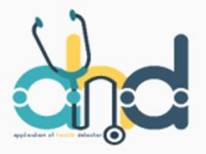

Grafik Pembacaan $\begin{array}{llllll}0 & 10 & 20 & 30 & 40 & 50 \\ & & & & \\ 160 & \end{array}$
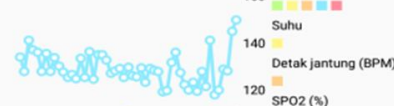

$\mathrm{SPO2}\left(\varphi^{2}\right.$

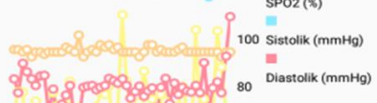

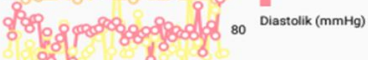

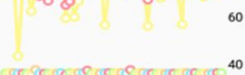

Suhu Tubuh Detak Jantung Sistolik

Diastolik

Kadar Oksigen Dalam Darah

Usia

Jenis Kelamin $(P / L)$

STATUS KESEHATAN

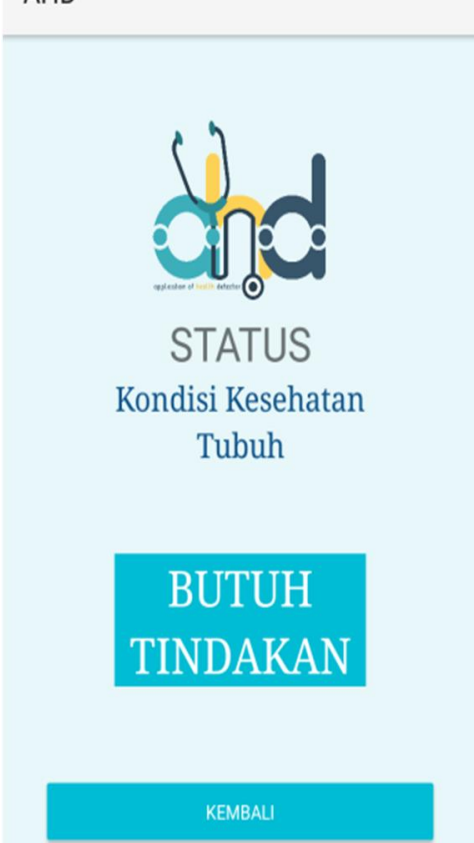

Gambar 9. Tampilan Data Real-Time pada Tanggal 21-06-2021 pada Keadaan Butuh Tindakan 


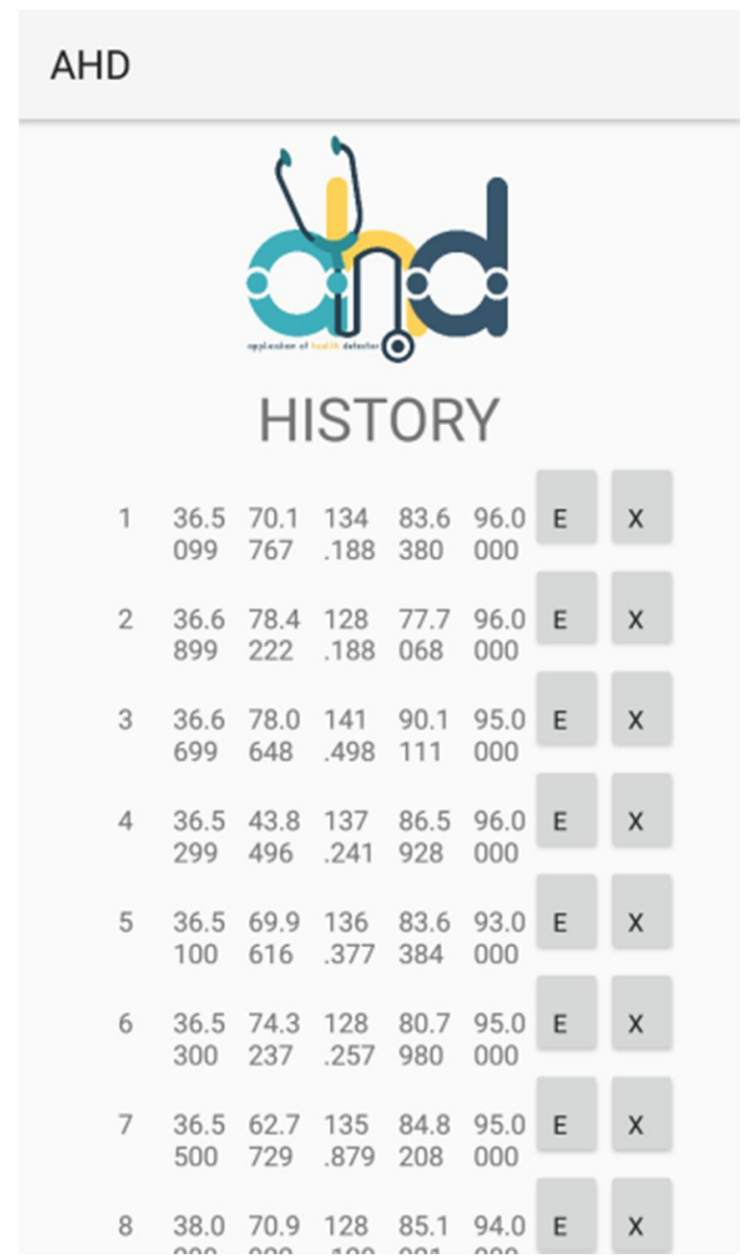

Gambar 10. Tampilan History Tanggal 21-06-2021

Berdasarkan data Real Time pada gambar 7, 8 dan 9 pada aplikasi AHD memiliki kinerja yang baik karena dapat mengirimkan data secara real time dengan menampilkan grafik beserta status kesehatan berupa Sehat, Indikasi atau Butuh Tindakan. Pada gambar 10, menampilkan history pembacaan sensor, serta button X yang berarti delete dan button $\mathrm{E}$ berupa edit, pada tampilan edit akan menampilkan status kesehatan dari pembacaan sensor.

\subsection{Analisa Kinerja Aplikasi AHD}

Dalam pengujian yang sudah dicoba, diawali dengan perancangan perangkat keras, perancangan perangkat lunak dengan memasukkan metode fuzzy mamdani, serta menggabungkan perangkat keras dan lunak.

Perancangan perangkat keras dimulai dari pemilihan komponen berdasarkan fungsi dan kegunaannya. Pada perancangan hardware menggunakan mikrokontroller nodemcu yang sudah dilengkapi dengan modul WIFI ESP8266 didalamnya, menggunakan sensor MLX 90614 sebagai sensor suhu tubuh, sensor MAX 5050 GP sebagai sensor tekanan darah, sensor MAX 30100 sebagai sensor detak jantung dan kadar oksigen dalam darah. Selain itu, digunakan pula Motor Driver sebagai driver untuk Motor DC dan Selenoid ke Node MCU, Motor DC sebagai motor untuk memompa tekanan udara, dan Selenoid sebagai katup untuk mengunci penahan dan pembuang udara. Agar dapat mengirimkan data pembacaan sensor ke server dan dikirim secara real time, NodeMCU ESP8266 yang sudah terkoneksi wifi mengirimkan informasi data hasil pengukuran sensor ke server yang akan ditampilkan di aplikasi android.

Untuk perancangan aplikasi menggunakan software IDE Android Studio. Aplikasi AHD yang dirancang menyediakan sebagian fitur ialah meliputi tampilan data real-time, status kesehatan maupun 
history. Kualitas aplikasi AHD memperoleh hasil pengukuran funtionalty "sangat tinggi" sebab seluruh fitur AHD bisa beroperasi dengan mudah. Pada pengukuran efficiency, aplikasi AHD mempunyai respons yang cepat dalam menunjukkan layout ataupun mengambil data informasi yang tersimpan di database server. Untuk pengukuran usability dinyatakan "sangat tinggi" karena aplikasi dapat digunakan mudah oleh pengguna.

Informasi yang akan ditampilkan di aplikasi android yakni hasil dari integrasi sensor node yang mengirimkan nilai-nilai kesehatan secara wireless ke server, setelah itu data tersebut disimpan kedalam database. kemudian android akan membaca informasi data di server dengan menggunakan protokol HTTP supaya dapat mengakses informasi untuk ditampilkan pada android setiap pengguna. Sebab sistem ini berbasis IoT, sehingga diperlukannya koneksi internet yang mencukupi supaya didapatkan data yang akurat serta real time.

\section{KESIMPULAN}

Aplikasi AHD selaku aplikasi sistem pendeteksi kesehatan tubuh berbasis android memiliki kemampuan yang cukup baik untuk mengetahui kesehatan tubuh berbentuk informasi data real-time, status kesehatan, maupun history. Pada tampilan data real-time, aplikasi AHD sukses menunjukkan informasi data terbaru dari kesehatan tubuh dan menunjukkan grafik setiap sensor secara bersamaan. Pada tampilan status kesehatan, aplikasi AHD berhasil menampilkan deteksi kesehatan tubuh berupa sehat, indikasi atau butuh tindakan. Pada tampilan history, aplikasi AHD sudah sukses menunjukkan semua list data pembacaan kesehatan tubuh pada waktu sebelumnya, yang juga disamping tampilan nilai-nilai tersebut terdapat button X sebagai delete dan button E sebagai edit.

Berdasarkan standar ISO 9126, sistem deteksi kesehatan tubuh dengan aplikasi AHD mempunyai persentase funtionality sebesar 100\%, artinya seluruh fitur aplikasi AHD bisa dioperasikan dengan lancar. Pada pengukuran efficiency, dilakukan dengan metode menghitung rata-rata waktu respon aplikasi AHD untuk launching pada setiap tampilan. Pada pengujian tersebut, diperoleh kesimpulan jika tipe prosesor serta RAM mempengaruhi performa aplikasi. Pada uji usability memiliki persentase $83 \%$, artinya aplikasi AHD dapat dijalankan dengan mudah oleh pengguna. Secara keseluruhan, sistem deteksi kesehatan tubuh berbasis aplikasi android dinilai sangat layak serta flexible bila dibandingkan dengan memakai pc ataupun laptop.

\section{SARAN}

Penelitian perlu untuk disempurnakan lagi kedepannya yakni pengembangan aplikasi yang lebih baik lagi dan layout tampilan yang di desain lebih menarik dan lebih banyak untuk memuat data supaya aplikasi yang digunakan lebih maksimal serta berguna bagi banyak pengguna.

\section{UCAPAN TERIMA KASIH}

Penulis sangat berterima kasih kepada Politeknik Negeri Sriwijaya atas fasilitas yang disediakan dalam proses penelitian ini. Penulis juga mengucapkan terima kasih kepada Posyandu Bukit Indah dan warga setempat atas bantuan dalam menjalankan penelitian ini. Ucapan terima kasih juga disampaikan kepada seluruh peneliti di Laboratorium Telekomunikasi dan Sinyal dan Kendali, Teknik Elektro, Politeknik Sriwijaya yang telah memberikan pendampingan dan sharing ilmunya. 


\section{DAFTAR PUSTAKA}

[1] WHO, 2021, “COVID-19 Weekly Epidemiological Update 35," World Heal. Organ., No. December, pp. 1-3, [Online]. Available: https://www.who.int/docs/defaultsource/coronaviruse/situation-reports/weekly_epidemiological_update_22.pdf.

[2] R. Srinivasan and E. Kannan, 2015, "A Review On Energy Efficient Routing Protocols In Wireless Sensor Networks,” Int. J. Appl. Eng. Res., Vol. 10, No. 11, pp. 27701-27715, doi: 10.26634/jwcn.4.4.5912.

[3] A. S. Handayani, 2019. “Penerapan Wireless Sensor Network Sebagai Monitoring Lingkungan Berbasis Android,” pp. 224-230,

[4] T. Wu, F. Wu, J. M. Redoute, and M. R. Yuce, 2017, “An Autonomous Wireless Body Area Network Implementation Towards IoT Connected Healthcare Applications,” IEEE Access, Vol. 5, pp. 11413-11422, doi: 10.1109/ACCESS.2017.2716344.

[5] Khan, 2009, "Medical Applications of Wireless Body Area Networks," Int. J. Digit. Content Technol. its Appl., Vol. 3, No. 3, pp. 185-193, doi: 10.4156/jdcta.vol3.issue3.23.

[6] C. A. Otto, E. Jovanov, and A. Milenkovic, 2006, “A WBAN-based System for Health Monitoring At Home,” Proc. 3rd IEEE-EMBS Int. Summer Sch. Symp. Med. Devices Biosensors, ISSS-MDBS 2006, pp. 20-23, doi: 10.1109/ISSMDBS.2006.360087.

[7] K. A. R Harini, BR Murthy, 2017. "Development of ECG Monitoring System Using Android app,” Int. Conf. Emerg. Trends Eng. Sci. Manag.,

[8] M. Babu Prasad, 2018. "GSM Based Health Care Monitoring System," Int. J. Innov. Technol. Explor. Eng., Vol. 8, No. 2 Special Issue 2, pp. 253-255,

[9] J. C. Herrera, D. B. Work, R. Herring, and X. Jeff, 2009. “UC Berkeley,"

[10] A. S. Handayani, A. F. Sayid, S. Soim, N. L. Husni, R. Rumiasih, and R. Permatasari, 2020, "Aplication ADeV Aplikasi Air Detection Environment System (ADeV) Dalam Mendeteksi Kadar Kualitas Udara di Area Parkiran Berbasis Android,” JATISI (Jurnal Tek. Inform. dan Sist. Informasi), vol. 7, no. 3, pp. 379-394, doi: 10.35957/jatisi.v7i3.507.

[11] Z. Hanum and MediaIndonesia.com, 2021. "Kemenkominfo: 89\% Penduduk Indonesia Gunakan Smartphone," www.mediaindonesia.com, https://mediaindonesia.com/humaniora/389057/kemenkominfo-89-penduduk-indonesia-gunakansmartphone (accessed Jul. 07, 2021).

[12] T. N. Sari, 2016, “Analisis Kualitas dan Pengembangan Sistem Informasi Akademik Berbasis Web Menggunakan Standard ISO 9126,” JIKO (Jurnal Inform. dan Komputer), Vol. 1, No. 1, pp. 1-7, doi: 10.26798/jiko.2016.v1i1.15.

[13] S. Supriyono, 2019, “Penerapan ISO 9126 Dalam Pengujian Kualitas Perangkat Lunak pada Ebook,” Matics, Vol. 11, No. 1, p. 9, doi: 10.18860/mat.v11i1.7672.

[14] G. Wang, D. Y. Bernanda, J. F. Andry, A. N. Fajar, and Sfenrianto, 2019, "Application Development and Testing Based on ISO 9126 Framework,” J. Phys. Conf. Ser., Vol. 1235, No. 1, doi: 10.1088/1742-6596/1235/1/012011. 